\title{
What impact have Covid-19 pandemic era on violence against women in India - A retrospective comparative research study from January 2018 to December 2021
}

Dr Piyush Kumar ( $\nabla$ drpiyush003@gmail.com )

Bihar Health Services- Government of Bihar, India https://orcid.org/0000-0001-9857-478X

Advocate Anupama ( $\square$ advocateanupama007@gmail.com )

Senior Lawyer, Bihar, India

\section{Research Article}

Keywords: SARS-CoV-2, pandemic, violence, women, lockdown, domestic abuse

Posted Date: January 14th, 2022

DOI: https://doi.org/10.21203/rs.3.rs-1256722/v2

License: (c) (i) This work is licensed under a Creative Commons Attribution 4.0 International License.

Read Full License 


\section{Abstract}

\section{Background}

The safety of women is of significance and prime concern in India due to a huge female population, equity issues, gender issues, lack of positive deviance at community level, illiteracy, socio-economic factors, migration from rural to urban areas, inaccessibility to legal help and of course many more factors. The SARS-CoV-2 pandemic had presented a challenge even for developed nations around the world regarding women's protection in the ongoing pandemic era \& especially in the lockdown period when it's really difficult to go out and shout for help.

\section{Aim and Objectives}

The main aim of this research is to find out impact of SARS-CoV-2/Covid-19 Pandemic on violence against women in India across different states and union territories from the beginning of pandemic i.e. January 2020. The objective is to find out that the covid-19 era has a positive or negative impact over violence against women. Data from various accredited sources were continuously collected, observed and analysed for this research study.

\section{Settings \& Design}

The month-wise and state-wise data indicating number of complaints registered with National Commission for Women in India(NCW) under different categories are presented in different table 1, 2, 3, $4,5,6,7,8$ will be discussed and displayed. The period of study is from January 2018 to 2021 December. This is a retrospective cross-sectional continuous observational qualitative and quantitative as well as comparative study. The two years of covid-19 pandemic i.e. 2020 and 2021 is compared two previous two years to know the impact of covid-19 on violence against women in India.

Materials \& Methodology

The data is collected from accredited and reliable sources of National commission for women, India as well as various other sources listed in this research study. The data obtained is analysed by using Microsoft Office software. To reduce the length of article the detailed description and analysis is not provided in this version.

\section{Result}

Increase in violence against women in India is seen in this covid-19 pandemic era as compared to prepandemic years under observation. See Figure 1 and figure 2:- comparison of number of cases of domestic violence and various forms of violence to know the impact of SARS-CoV-2 pandemic and lockdown situations in India. During the second year of pandemic i.e. 2021 the total numbers of NatureWise Report of the Complaints Received by NCW was 30865 which is an increase by $55.03 \%$ compared to 2018 and $56.43 \%$ as compared to 2019 . 
India should have various strategies to ensure safety of women and their mental health issues in such pandemic like situations. It seems that present laws and regulations are insufficient to give the desired results. The barriers of legal and protective system and delivery of helpful services etc. constraints should be rectified added with a proper dynamic plan to carry on usual women protection services even in pandemics and natural disasters.

\section{Introduction}

Violence is a burden on the social system and affects the development of a nation. It cost nations capital in terms of health care, law enforcement, DALYs (disability adjusted life years) and general progress in development. The violence based on gender is usually inflicted upon a female on the basis of her sex. It includes multiple acts like physical, mental, social, or sexual harm. These have an adverse effect on health status of a woman and also affect her productivity, the belief of self- esteem and sufficiency, confidence as well as overall quality of life.

In an estimates on violence published by WHO they found that globally about 1 in 3 (30\%) of women across all nations have experienced either physical and/or sexual violence or non-partner sexual violence during their lifetime. The implementation of lockdowns to control the COVID-19 pandemic has social and economic impacts. This have increased the exposure of women to abusive inmates and limiting their access to services. This situation of humanitarian crises and displacement may increase existing violence, such as by intimate partners, as well as other-partner sexual violence, and may also lead to increase of violence against women [1]. The author request readers to go through previous preprint on this research study for better understanding $[2,3$, and 4$]$

The protection of women is of utmost importance and prime concern in India due to a huge population, equity issues, lack of positive deviance at community level, illiteracy, socio-economic factors, migration from rural to urban areas, inaccessibility to legal help and of course many more factors. The SARS-CoV-2 pandemic had presented a challenge even for developed nations around the world regarding women's protection in the ongoing pandemic era \& especially in the lockdown period when it's really difficult to go out and shout for help.

The police force and other protective forces have been largely deployed to tackle the situation of pandemic of Covid-19. This shift has tremendous effect on ongoing various violence against women's in the pandemic era. Pregnant mother \& children's are especially more vulnerable groups. The women's usually have a sense of fear in meeting others particularly in pandemic acute emergency situations. Moreover most of the women's have to stay in home due to lockdown enforcement and added to this as per protocols the community and system both have constrains erupting from the sudden situations of pandemic. The mental health of women's having violence as well as workload with social-issues is a major concern globally added to income loss and various socio-economic determinants of health. Loss of jobs , stress, reduced income, lockdown, violence, domestic conflicts and several other factors related 
to daily livelihood creates a vicious cycle and the women gets entangled in this cycle particularly in pandemic and lockdown situations.

The advocacy for maternal health, women empowerment have been done and emphasised by many national and international organisation for several decades considering them especially vulnerable groups in times of disaster such as pandemic. The Covid-19 pandemic has clearly disclosed the weakness of protective system to protect above mentioned vulnerable groups. The situation also produced a demand of separate cadre to protect women in situations of disaster like pandemic. It seems many protective services were not delivered in covid-19 era which may produce undesirable and detrimental effects at mass level in coming future.

\section{OBJECTIVES}

Domestic abuse, also known as domestic violence or the intimate partner violence, is defined as the pattern of behaviour in any relationship which is used to gain power and over control an intimate partner. This abuse may be physical, sexual, emotional, economical or psychological activities or threats of activities that can influence another person. These include any kind of behaviour that can cause frightening, intimidating, terrorizing, manipulating, hurting, humiliating, blaming, injuring, or wounding someone. Domestic abuse is also a kind of violence that can happen to anyone of any race, age, sexual orientation, religion, or gender. This can occur within a range of relationships including couples who are married, living together or dating. Domestic violence can affects people of all socioeconomic backgrounds and education levels [1].

\section{The main aim of this research study is to find out Impact of SARS-CoV-2/Covid-19 Pandemic on violence} against women in India across different states and union territories from the beginning of pandemic due to covid-19 i.e. January2020. Although the WHO has announced covid-19 pandemic on 11 March 2020, India has reported first case in January 2020 and from that time several restrictions and directives came into action one by one resulting in stress and chaos all around continuing till date [5]. The women and children are considered a special vulnerable group and the globe is also witnessing a decline in several necessary health services needed especially for women and child protection $[6,7,8,9,10,11]$

Data from January2018 to December 2021 is taken for the research study in order to have a comparative analysis of two years of pandemic era i.e. 2020 and 2021 from pre-pandemic two years i.e. 2018, 2019. The data is available in table number

\section{Materials And Methodology}

The national commission for women (NCW) in India have launched an Ad campaign from the beginning of the lockdown in March 2020. The lockdown was announced on $24^{\text {th }}$ march 2020 for 21 days. Various Ads through electronic as well as social media were instituted to know about the women's who have 
suffered any kind of violence to come forward and report to concerned department and authorities in several ways. The press information bureau [12] Government of India Ministry of Women and child development have publicly announced under the heading-Increase in domestic violence against women dated 22 Sep 2020.

The NCW had also launched a what's-app number as well as helpline number for reporting domestic violence situations in addition to other previously established chains of communications. The received complaints were duly addressed by concerned department and authorities. The complaints received were recorded in two headings as shown in table 1 and table2. Table 1 category includes protection of women against domestic violence received from March 2020 till 20 ${ }^{\text {th }}$ September 2020. Table 2 includes total complaints registered / received by NCW related to crime against women as well as deprivation of their rights since March 2020 till $20^{\text {th }}$ September 2020. Also see table 3 \& figure 1. Table 4,5,6,7, includes data on various violence against women in India from 2018-2019-2020-2021 respectively whereas table - 8 shows comparison of these violence for different years. Figure-2- 3 shows comparison of various kinds of violence against women in India from 2018-2019-2020-2021 respectively.

\section{Settings \& Design}

The data is collected from accredited and reliable sources of National commission for women, India as well as various other sources listed in this research study. This is a retrospective cross-sectional continuous observational qualitative and quantitative as well as comparative study. The month-wise and state-wise data indicating number of complaints registered with National Commission for Women in India(NCW) under two different categories in two different table $1 \& 2$ will be discussed and displayed. This period of study is from March 2020 to $20^{\text {th }}$ september2020. The data is compared to previous year 2019 data. Another study period is from January-2018 to December-2021.

The data is also shown in tabulated as well as graphical form for ease of understanding. All the data obtained were analysed using Microsoft office software. The analysis report is presented as graphs and also in letters. See table 1, 2, 3, 4, 5,6,7,8 \& figure 1 and 2, 3.

\section{Data Availability}

https://ncrb.gov.in/

https://pib.gov.in/indexd.aspx

http://ncwapps.nic.in/frmComp_stat_Overview.aspx

\section{Methodology}

All the data obtained were analysed using Microsoft office software. The analysis report is presented as graphs and also in letters. The data for analysis is obtained from the source mentioned in this study. The data is collected from accredited and reliable sources of National commission for women, India as well 
as various other sources listed in this research study. To reduce the length of article the detailed description and analysis is not provided in this version.

\section{Results}

The National Commission for Women have received 30865 complaints of crimes committed against women in 2021, the highest in the last four years. Increase in domestic violence against women in India from March 2020 till $20^{\text {th }}$ September 2020. See Figure 1and 2:- comparison of number of cases of domestic /other violence to know the impact of SARS-CoV-2 pandemic and lockdown situations in India. The total number of State-wise and month-wise data indicating number of complaints registered with NCW under the category-Protection of Women against domestic violence, received during the last six months, i.e. from March 2020 till 18th September, 2020- is 4350 (Uttar Pradesh reported maximum).Total number of Month-wise and Statewise data of complaints registered/ received by NCW since March 2020 is 13410(Uttar Pradesh reported maximum). The data is compared to NCRB (national crime record bureau) data 2019[13] the total number of female victim of domestic violence was 554 \& total number of incidence was 553 and the crime rate $0.1 \%$ per lakh population - See table 1, 2, 3 \& figure 1 . The total numbers of Nature-Wise Report of the Complaints Received by NCW in the Year: 2018 was 19908 whereas it reduced a little $0.8 \%$ during 2019 during which it was 19730. The average total numbers of Nature-Wise Report of the Complaints Received by NCW for 2 pre-pandemic years i.e. 2018 and 2019 was 19819. During the first year of pandemic i.e. 2020 the total numbers of Nature-Wise Report of the Complaints Received by NCW was 23722 which is an increase by $19.15 \%$ compared to 2018 and $20.23 \%$ as compared to 2019 . During the second year of pandemic i.e. 2021 the total numbers of Nature-Wise Report of the Complaints Received by NCW was 30865 which is an increase by $\mathbf{5 5 . 0 3} \%$ compared to 2018 and $56.43 \%$ as compared to 2019 . Hence it is concluded from the above observation research study that the violence against women in India have increased in covid-19 pandemic era as compared to immediate two years of pre-pandemic era. The maximum number of complain received in all the four years of observation is of Right to live with dignity and the covid-19 pandemic era second year i.e. 2021 have maximum numbers of such Complaints Received by NCW see table 4,5,6,7,8. Protection of Women against Domestic Violence is next to the above mentioned complain with the second year of covid-19(2021) having maximum numbers. Discussing individual complain rates increase will be done in next version of the research study.

\section{Discussion}

In the year 1983, domestic violence was categorized as a criminal offence in India. The punishment and imprisonment of the culprits does not necessitate the fact that justice has been delivered through and through. Recovery of the victim to be able to lead a normal life should be the main goal. The Crime in India Reported by the National Crime Records Bureau (NCRB) states that crime against women happens at the rate of at least one crime against women per 1.7 minutes in India, and domestic violence at least one per 4.4 minutes [14]. During lock down women may be subjected to psychological abuse of different 
types like threats of being abandoned, demeaning, belittlement and insults, threats of hurting someone they care about or increased general infidelity of the husband. The psychological effects on mental health due to abuse are more deep-seated and unrealized. Mostly domestic abuse victims get diagnosed with depression and PTSD (post traumatic stress disorder). Violence induced depression in abused women may be chronic and has a life-long effect on the victim even in the absence of abuse for a long time. The working women have lost their jobs during the covid-19 pandemic and sources of earning, which can lead to the loss of empowerment that these women had earlier.

\section{LAWS DEALING WITH DOMESTIC VIOLENCE IN INDIA}

There are several laws framed by the constitution of India which protect a woman from being abused by anyone. Discussing all the laws is beyond the scope of this article. Since there is an exceptional increase in complaints registered against domestic violence a little discussion is presented by the authors of section 498A IPC.

\section{SECTION 498A OF INDIA PENAL CODE}

It states that if a woman's is subjected to harassment by husband or his relatives or any act of cruelty against her, the culprits will be liable for imprisonment up to three years as well as fine. The definition of term cruelty under the same section is stated as any act that leads to compulsion for dowry demands from the woman or her family members or any act that abets the woman to do suicide or inflict grievous injury upon herself (mental or physical).

\section{PROTECTION OF WOMEN FROM DOMESTIC VIOLENCE ACT 2005-PWDVA}

This act prohibits a wide range of mental, sexual, physical, and economic violence against women, and all of these are exhaustively mentioned under the Act. The domain of the Act also includes women who are in a live-in relationship as well. Under this Act provision, a woman has the full right to be free from abuse and can choose herself from different recourses. She has the right to get a restrictive order against her husband and his relatives, to be able to continue living in the same house, to claim maintenance, to have full custody of her children and to claim required compensation and to not be terrified out of her marital home.

\section{FAMILY COURT ACT, 1984}

The 59th report of the Law Commission laid significance on the establishment of distinct courts for dealing matrimonial, personal and family issues. After establishment, such courts have helped in speedy disposal of matrimonial and personal issues that are long pending in civil and criminal courts.

India should have various strategies to ensure safety of women in such pandemic like situations. It seems that present laws and regulations are insufficient to give the desired results. The barriers of legal and protective system and delivery of helpful services etc. constraints should be rectified added with a proper dynamic plan to carry on usual women protection services even in pandemics and natural 
disasters. India needs to develop an exclusive plan to tackle such situations such as establishment of separate cadre of worker for women protection services. India is having a very huge population of women's vulnerable to different kinds of violence so the Government must give top priority in making India a safe place for women's. The women's who are illiterate must not have access to all these reporting system as well as women from poor economical background added with remote village areas with less communication mechanisms. Lockdowns imposition during the COVID-19 pandemic have social and economic impacts have increased the exposure of women to abusive partners and known risk factors, while limiting their access to services [15]. Lockdown induced situations of humanitarian crises and displacement can increase existing violence, such as by intimate partners, as well as other-partner sexual violence, and may also lead to novel forms of violence against women.

The World Health Organization have published that over one-fourth of women between age 15-49 years have been in a relationship and subjected to physical and/or sexual violence by their intimate partner at least once in their lifetime (since age 15). The World Health Organization also found that prevalence estimates of lifetime intimate partner violence range from $20 \%$ in the Western Pacific, $22 \%$ in HIC (highincome countries and Europe) and 25\% in the WHO Regions of the Americas to $33 \%$ in the WHO African region, $31 \%$ in the WHO Eastern Mediterranean region, and 33\% in the WHO South-East Asia region. The WHO found that worldwide as many as $38 \%$ of women murders are committed by intimate partners, in addition to this partner violence, worldwide $6 \%$ of women report having been sexually harassed-assaulted by someone other than a partner, although data for non-partner sexual violence are more limited. Intimate partner and sexual violence are mostly found to be perpetrated by men against women [1]. The domestic violence has much impact on mental health status of women and children's. The lockdown and pandemic era have developed a sense of fear among the women's. The fear can lead to self harm such as suicide etc. and added to this there is loss of income which has many serious socio-economic impacts resulting in a vicious cycle finally leading to mental health issues.

\section{Conclusion}

India needs to develop an exclusive plan to tackle such situations such as establishment of separate cadre of worker for women protection services. India is having a very huge population of women's vulnerable to different kinds of violence so the Government must give top priority in making India a safe place for women's. The domestic violence have a serious impact on mental health of women's and their children especially in pandemic and lockdown situations in which its quite difficult to get help and relief. India should have various strategies to ensure safety of women and their mental health issues in such pandemic like situations. It seems that present laws and regulations are insufficient to give the desired results. The barriers of legal and protective system and delivery of helpful services etc. constraints should be rectified added with a proper dynamic plan to carry on usual women protection services even in pandemics and natural disasters. The COVID-19 pandemic has worsened the situation by increasing the violence against women in India. The National Commission for Women (NCW) registered an increase of

\section{4 per cent in domestic violence cases where women were assaulted in their homes during the lockdown.}

The migrant women have walked several miles with men due to lockdown strategy of the government of 
India, some with their children in stage of pregnancy, without availability of basic amenities like water, food etc. Therefore, due to the pandemic, nearly half a billion population of women are at risk of violence of several kinds in India. Yet, till date no special policy or any detailed COVID care plan for this special vulnerable group has been proposed by the government to control the situation.

- Establishment of exclusive special women protection cell in disaster like pandemic situations at central level as well as at all the states and union territories of India.

- Covid-19 pandemic has given us a lesson that we must have gender equity in society\& women's who are considered most vulnerable in situations of distress must have adequate supportive protection all the times especially during pandemics and other natural calamities. Women constitute a large portion of population and the country and state must have a separate department to ensure the protection to this vulnerable section of the population.

- India being the second most populous country in the world should have a robust women protection strategy to operate in any situations.

- The serious issue of mental health as well as socio-economic impacts of violence and lockdown should be properly taken care in pandemic like situation to protect especially vulnerable women's as well as their children's.

\section{Declarations}

-This version of paper has not been previously published in any peer reviewed journal and is not currently under consideration by any journal. The document is Microsoft word with English (United States) language \& 3634(excluding tables-chart-declaration etc.) (8622 words Total). The preprint of this research article is available online with DOI on various preprint servers.

- Ethics approval and consent to participate: Not applicable. This study has not involved any human or animals in real or for experiments. The data on the COVID-19 pandemic were taken from the Health Department available as electronic patient records from HMIS (health management information system) of MoHFW (ministry of health and family welfare), Government of India.

-Consent for publication: The authors provide consent for publication to anyone for increasing and sharing knowledge to people who need it.

-Availability of data and materials: Electronic patient records from HMIS (health management information system) of MoHFW (ministry of health and family welfare), Government of India.

-Conflicts of Interest/ Competing Interest: There are no conflicts / competing of interest

- Funding-Self sponsored. No aid taken from individual or agency etc.

- Authors' contributions: The whole work is done by the Author - Dr Piyush Kumar, M.B.B.S., E.M.O.C., P.G.D.P.H.M., -Senior General Medical Officer- Bihar Health Services- Health Department- Government of 
Bihar, India and Advocate Anupama as mentioned above.

- Acknowledgements-I am thankful to Advocate Anupama my wife and daughters Aathmika-Atheeva for cooperation.

- Author information: The author is currently working as Senior General Medical Officer for the government of Bihar, co-author is senior lawyer.

-Financial Support \& sponsorship: Nil

-Author contact information

Department of Health, Government of Bihar, MOBILE -

+919955301119/+917677833752, Email drpiyush003@gmail.com

\section{References}

1. COVID-19 and violence against women - $h$ htps://www.who.int/publications/i/item/WHO-SRH-20.04 World Health Organization

2. Kumar, Piyush and Kumar, Piyush, What Impact Have SARS-CoV-2/COVID-19 Pandemic on Domestic Violence against Women in India across Different States and Union Territories from the Beginning of Lockdown Due to COVID-19 Pandemic in March 2020 Till 20Th September 2020? How COVID-19 Pandemic Induced Lockdown Influence Mental Health of Women in India? (April 15, 2021). Available at SSRN: https://ssrn.com/abstract=3826837 or http://dx.doi.org/10.2139/ssm.3826837

3. Dr Piyush Kumar. What Impact Have SARS-CoV-2/Covid-19 Pandemic on domestic violence against women in India across different states and union territories from the beginning of lockdown due to covid19 pandemic in March 2020 till 20th September 2020? How Covid-19 pandemic induced lockdown influence mental health of women in India?, 14 April 2021, PREPRINT (Version 2) available at Research Square [https://doi.org/10.21203/rs.3.rs-414848/v2]

4. Dr Piyush Kumar. What Impact Have SARS-CoV-2/Covid-19 Pandemic on domestic violence against women in India across different states and union territories from the beginning of lockdown due to covid19 pandemic in March 2020 till 20th September 2020?\&nbsp; 12 April 2021, PREPRINT (Version 1) available at Research Square [https://doi.org/10.21203/rs.3.rs-414848/v1]

5. Dr Piyush Kumar. What impact have Covid-19 pandemic on number of death occurring at the Emergency Department: A Retrospective Analysis of Mortality in India from January 2019 to May 2021, 12 January 2022, PREPRINT (Version 1) available at Research Square [https://doi.org/10.21203/rs.3.rs$1245972 / v 1]$

6. Dr Piyush Kumar, Dr Habib Hasan Farooqui. What is the Impact of Covid-19 Pandemic on the RCH (Reproductive and Child Health) Programme in Rajasthan, because of nationwide lockdown (April 2020 to 
June 2020)?, 30 August 2021, PREPRINT (Version 1) available at Research Square [https://doi.org/10.21203/rs.3.rs-855882/v1]

7. Kumar, Piyush and Kumar, Piyush, What Impact Have SARS-CoV-2/Covid-19 Pandemic induced lockdown on the number of OPD patients of Diabetes, Hypertension, Stroke (CVA), Acute Heart Disease, Mental Illness, Epilepsy, Ophthalmic, Dental and oncology in India during the lockdown months (AprilMay-2020)-Observational Research Analysis? (July 12, 2021). Available at SSRN: https://ssrn.com/abstract=3884524 or http://dx.doi.org/10.2139/ssrn.3884524

8. Dr. Piyush Kumar. What Impact Have SARS-CoV-2/Covid-19 Pandemic on the Reproductive and Child Health Programme of Bihar in India over the 3 months after nationwide Lock down announcement in March 2020? How SARS-CoV-2 Pandemic era does influence RCH Programme? Immunisation? \&nbsp;Maternal Health? Family Planning?, 30 March 2021, PREPRINT (Version 4) available at Research Square [https://doi.org/10.21203/rs.3.rs-348841/v4]

9. DR PIYUSH KUMAR. What Impact Have SARS-CoV-2/Covid-19 Pandemic on the Reproductive and Child Health Programme of India over the 3 months after nationwide Lock down announcement in March 2020 -A brief analysis., 25 March 2021, PREPRINT (Version 1) available at Research Square [https://doi.org/10.21203/rs.3.rs-360551/v1]

10. Piyush Kumar. What Impact Have SARS-CoV-2/Covid-19 Pandemic on the Reproductive and Child Health Programme of Uttar Pradesh in India over the 3 months after nationwide Lockdown announcement in March 2020 -A brief analysis, 25 March 2021, PREPRINT (Version 1) available at Research Square [https://doi.org/10.21203/rs.3.rs-350287/v1]

11. Immunisation? Maternal Health? Family Planning?. https://doi.org/10.31219/osf.io/dphgaøKumar, $P$. (2021, March 28). What Impact Have SARS-CoV-2/Covid-19 Pandemic on the Reproductive and Child Health Programme (Immunisation, Maternal Health, Family Planning) of Andhra Pradesh in India over the 3 months after nationwide Lock down announcement in March 2020?

12. Press information bureau[i], Government of India Ministry of Women and child development - https://pib.gov.in/allRel.aspx

13. NCRB (national crime record bureau) data - https://ncrb.gov.in/

14. Crime in India 2018, Statistics, 1 NCRB (2018),

https://ncrb.gov.in/sites/default/files/Crime\%20in\%20India\%202018\%20-\%20Volume\%201.pdf.

15. Kumar, Piyush and Kumar, Piyush, What Impact Has Lockdown on SARS-CoV-2/COVID-19 Incidence, Prevalence and Mortality During Second Wave of Pandemic in 2021: Observational Analysis of Bihar (6/20/2021). Available at SSRN: https://ssrn.com/abstract=3871321 or http://dx.doi.org/10.2139/ssrn.3871321 


\section{Tables}

Tables 1-8 are in the supplementary files section.

\section{Figures}

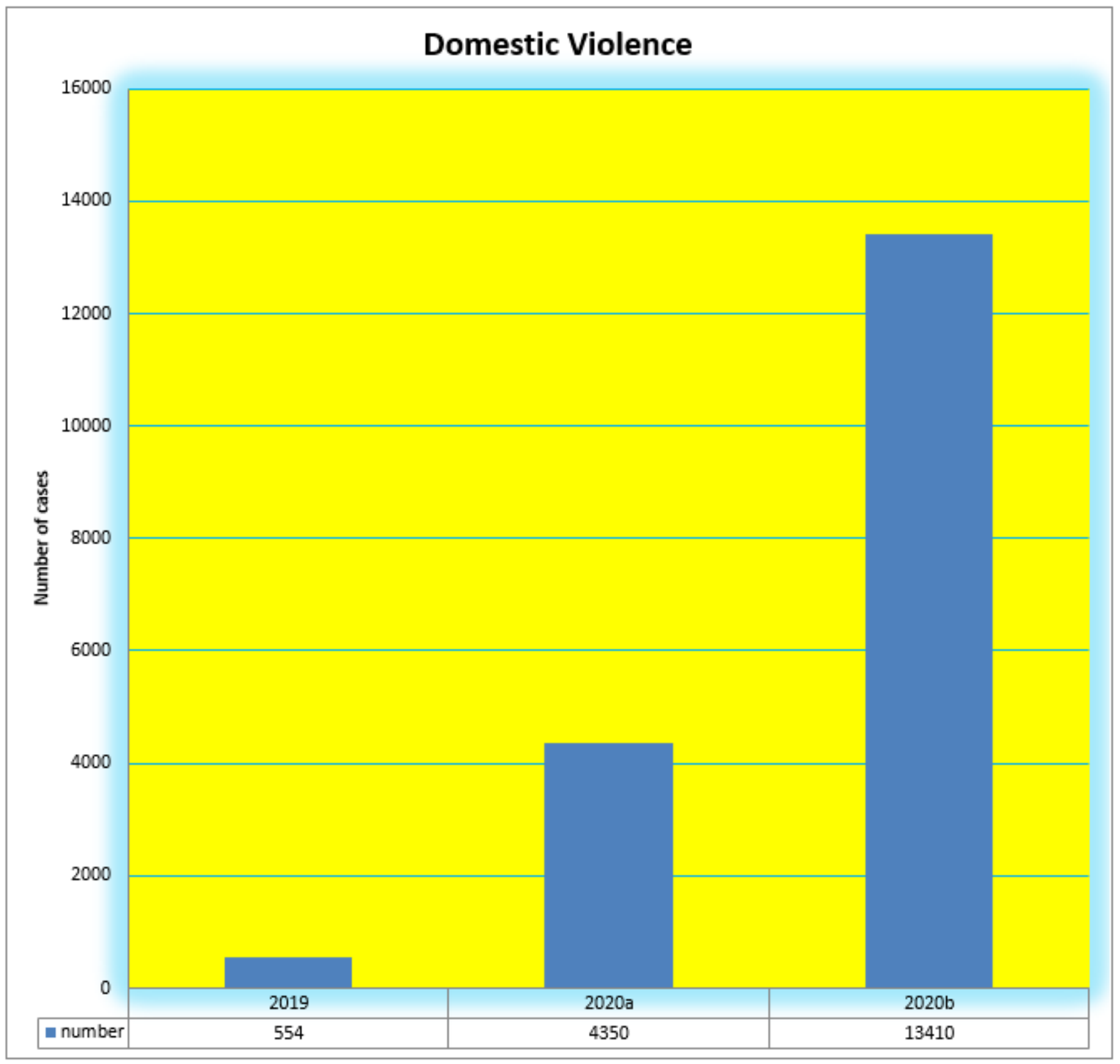

\section{Figure 1}

comparison of number of cases of domestic violence to know the impact of SARS-CoV-2 pandemic and lockdown situations in India (please see description below figure and article text).

2019- See table 3 SLL Crimes against Women (Crime Head-wise \& State/UT-wise) - 2019 V= No. of Female Victims- source- https://ncrb.gov.in/-2020a- See Table 1- The State-wise and month-wise data 
indicating number of complaints registered with NCW under the category "Protection of Women against domestic violence", received during the last six months, i.e. from March 2020 till 18th September, 2020Source-https://pib.gov.in/allRel.aspx-2020b-See-Table 2 - Month-wise and State-wise data of complaints registered/ received by NCW since March 2020 (till 20.09.2020)). Sourcehttps://pib.gov.in/allRel.aspx

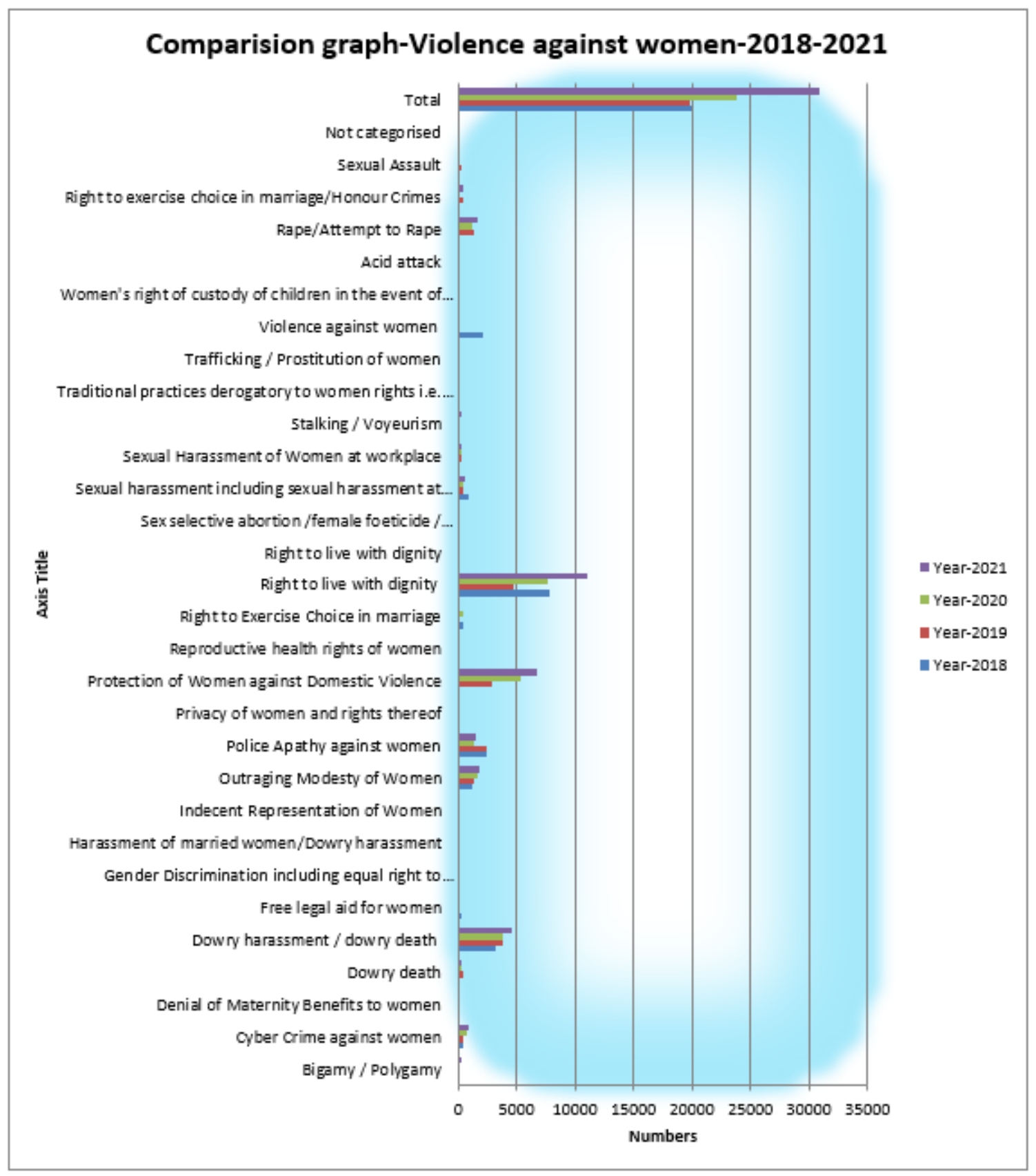

Figure 2

Year wise comparison of Violence of different types against women in India 


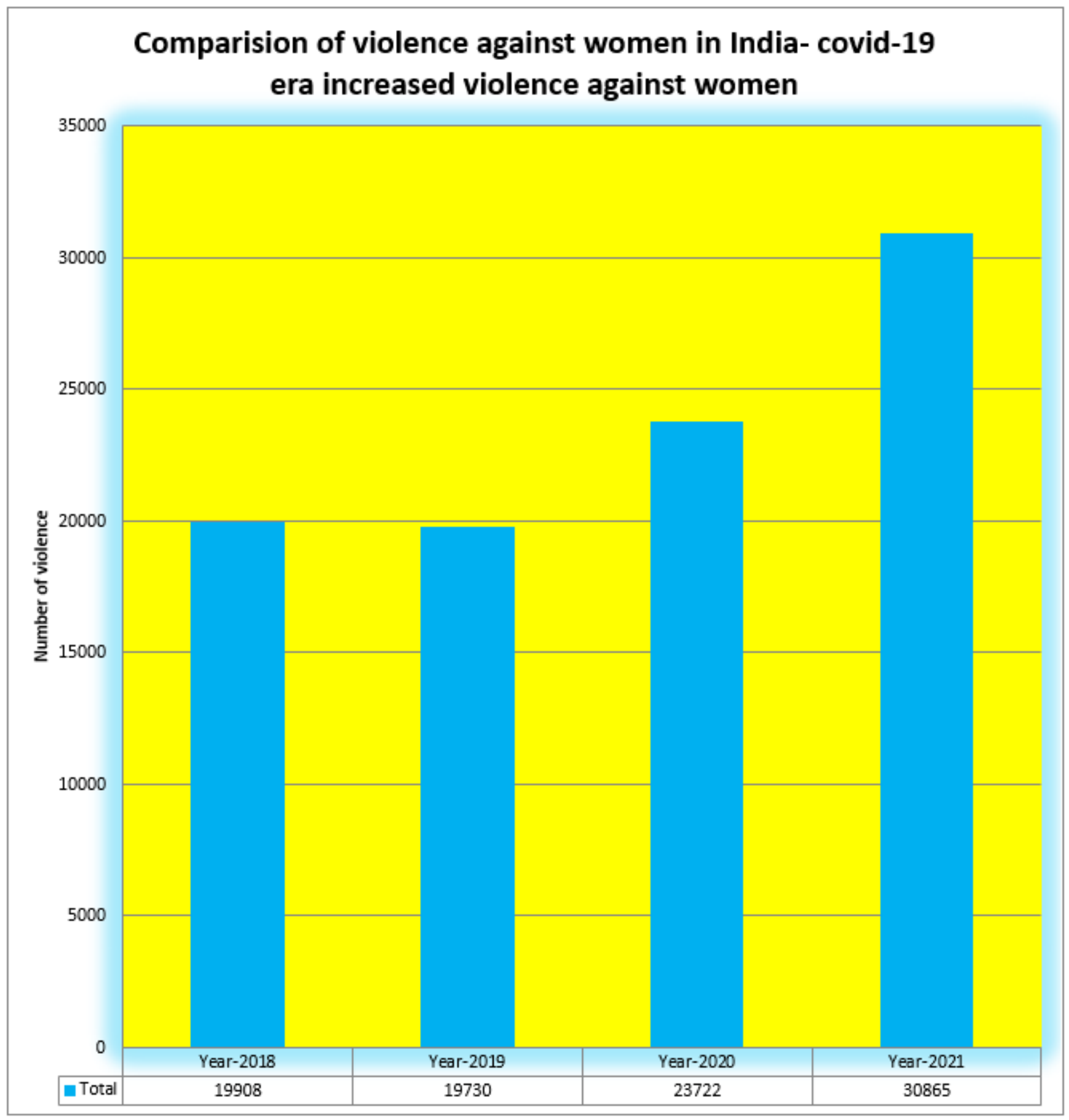

Figure 3

Comparison of violence against women in India shows that covid-19 era has increased violence against women in India

\section{Supplementary Files}

This is a list of supplementary files associated with this preprint. Click to download.

- Data.docx 
- 2018.pdf

- 2019.pdf

- 2020.pdf

- 2021.pdf

- Tables.docx 